\title{
Gestión del agua como factor limitante de productividad cañera en México ${ }^{1}$
}

\author{
Noé Aguilar-Rivera ${ }^{2}$, Marcos Algara Siller ${ }^{3}$ y Luis Alberto Olvera Vargas ${ }^{4}$
}

\section{RESUMEN}

Para México es fundamental aplicar técnicas de agricultura de precisión en la agroindustria azucarera con información meteorológica básica de precipitación, temperatura y evapotranspiración para obtener el potencial de humedad retenido por el suelo, en conjunto con percepción remota y el Índice de Diferencia Normalizada de Vegetación (NDVI). El trabajo se llevó a cabo en zafra 2008/2010 en Huasteca Potosina México. Se emplearon imágenes NOAA-AVHRR de satélites 17, 18 y 19 con bandas AVHRR $1\left(\rho_{1}\right)\left(0,58\right.$ a $0,68 \mu \mathrm{m}$ - rojo) y AVHRR $2\left(\rho_{2}\right)(0,72$ a $1,10 \mu \mathrm{m}$ - infrarrojo cercano) para generar imágenes NDVI, simultáneamente se calculó a partir de registros de 11 estaciones de la zona cañera para obtener el Índice de Satisfacción de las Necesidades Hídricas de los Cultivos (ISNH). El análisis indica que existe la correlación de valores NDVI con las condiciones climáticas y que inciden en la productividad de la zafra azucarera de la Huasteca Potosina.

Palabras clave: Caña de azúcar, rendimiento, índice de vegetación, necesidades hídricas.

\begin{abstract}
For Mexico it is fundamental to apply precise agricultural techniques in the sugarcane industry based on basic meteorological data such as precipitation, temperature and evapotranspiration in order to obtain the potential soil humidity, along with remote sensing techniques and the Normalized Difference Vegetation Index (NDVI). This study was performed during the 2008-2010 harvest seasons in the Huasteca Potosina region of Mexico. The analysis based on remote sensing techniques used NOAA-AVHRR images from satellites 17, 18 and 19 with AVHRR bands 1 ( $\rho 1$ ) (0.58 to $0.68 \mu \mathrm{m}$ - red) and AVHRR 2 ( $\rho 2)$ (0.72 to $1.10 \mu \mathrm{m}$ - Near Infrared) to generate NDVI images. Simultaneously meteorological data was calculated based on data from from 11 agroclimate stations located in the study region. This data was, in turn, used to calculate the Water Requirement Satisfaction Index (WRSI). Results show a correlation between NDVI values and climatic conditions, which influence sugarcane productivity in the Huasteca Potosina region.
\end{abstract}

Key words: Sugarcane, crop yield, normalized difference vegetation index, water requirement satisfaction index

1 Artículo recibido el 27 de febrero de 2014, aceptado el 4 de diciembre de 2014 y corregido el 23 de diciembre de 2014.

2 Facultad de Ciencias Biológicas y Agropecuarias, Universidad Veracruzana (México).

E-mail: naguilar@uv.mx
3 Universidad Autónoma de San Luis Potosí (México). E-mail: marcos.algara@uaslp.mx

4 Universidad Autónoma de San Luis Potosí (México). E-mail: olvera@uaslp.mx 
La agroindustria de la caña de azúcar es un sector productivo que ha funcionado con la comercialización de un solo producto: la sacarosa o azúcar de mesa como resultado de operaciones unitarias de proceso en una factoría denominada "Ingenio Azucarero" que procesa las variedades de caña de azúcar (Saccharum spp.) como materia prima única, procedente de un monocultivo y contribuye en forma sustancial al crecimiento económico y social. En este sentido, los productores de caña de azúcar a nivel mundial continúan buscando formas de reducir costos, aumentar la productividad y rendimientos en gran medida porque la capacidad de producir caña y sacarosa están determinados por las características genéticas de la variedad cultivada, factores morfológicos, enzimáticos, ambientales, disponibilidad de agua e incidencia de plagas y enfermedades (Cheavegatti-Gianotto et al., 2011). Así, resulta fundamental estudiar estos factores considerados limitantes (Singels et al., 2010) a fin de establecer las estrategias de regionalización de variedades y tecnologías de manejo con un fundamento científico y sobre bases sostenibles para modelar el desarrollo del cultivo e incrementar la rentabilidad y productividad. En este sentido, la caña de azúcar posee un período vegetativo muy variable, cuya duración depende básicamente de las características del material genético utilizado y de la influencia que factores limitantes agroclimáticos ejercen en su proceso biológico (Miceli, 2002; Hunsigi, 2001; Fogliata, 1995). En su desarrollo se consideran esencialmente cuatro fases fenológicas: a) fase de establecimiento que implica brotación y emergencia, ya sea en plantación (plantillas) o en rebrote o retoños (socas), b) fase de ahijamiento o de macollaje; c) fase de crecimiento rápido; y d) fase de maduración (FAO, 2009) (Figura $N^{\circ} 1$ ).

En México y sus regiones productoras existe una deficiencia en el modelado del cultivo y no se han aplicado herramientas multidisciplinarias que permitan caracterizar las problemáticas socioeconómicas y factores limitantes bióticos y abióticos asociados a su producción en el ámbito regional, que integren el análisis de las fases fenológicas con características edafológicas y climáticas, limitantes de la productividad, en un contexto de agricultura de precisión, biotecnología y mejoramiento genético (Aguilar-Rivera et al., 2013; Aguilar-Rivera \& Olvera, 2015) (Figura $N^{\circ} 2$ ).

Figura $\mathrm{N}^{\circ} 1$

Ciclo fenológico y productivo de la caña de azúcar hemisferio norte

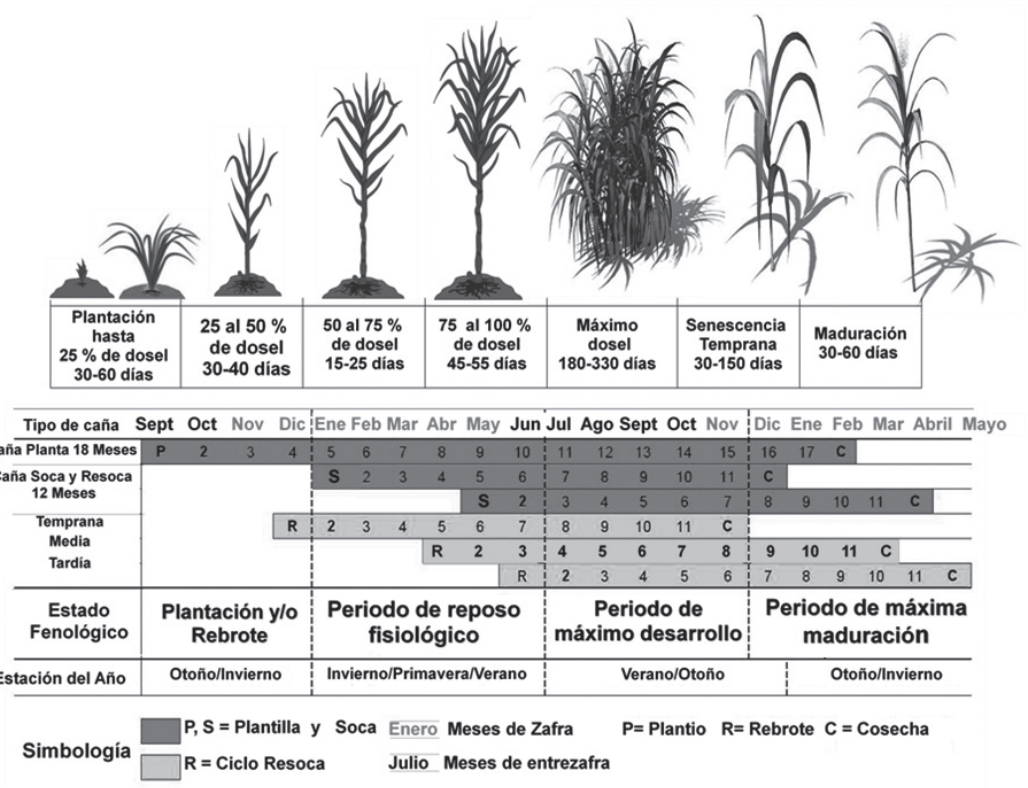

Fuente: Ramme (2008). 


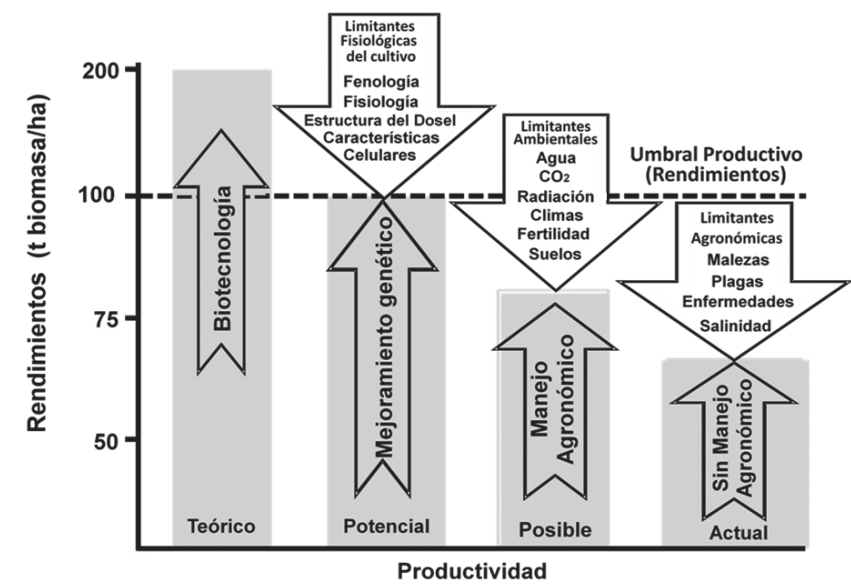

Fuente: Moore (2009).

En este sentido, en México los factores que son considerados en el cálculo de los estimados de productividad del cultivo son:

1. Comportamiento histórico de cada parcela (rendimiento de campo y agroindustrial).

2. Cantidad y calidad de las labores culturales aplicadas o por aplicar (limpia, cultivos, fertilización, herbicidas, riego, etc.)

3. Características del comportamiento de cada variedad y ciclo (crecimiento, desarrollo, resistencia a la sequía, resistencia a enfermedades y plagas, floración, etc.).

4. Comportamiento histórico de las Iluvias y demás variables del clima en la región.

5. Características de los suelos y su valor agroproductivo.

6. Porcentaje de población de tallos de cada parcela.

7. Grado de enyerbamiento (arvenses y malezas) que ha existido y tiempo que este ha estado afectando la parcela considerada con el uso de modelos estadísticos básicos que relacionan principalmente las tasas de precipitación y los rendimientos históricos o en el mejor de los casos, la aplicación de las ecuaciones generales como:

\footnotetext{
$\mathrm{Y}=0.077421407 \mathrm{DIM}-0.023011064 \mathrm{TOT}-$ I.117852193MO- 12,20337095 pH + $135.5787329 \quad\left(R^{2}=0,989\right)$
}

donde DIM es la lluvia de diciembre a mayo $(\mathrm{mm})$, TOT $(\mathrm{mm})$ la precipitación anual total, $\mathrm{MO}$ es la materia orgánica (\%) y el pH para estimar estadísticamente la productividad en los campos de cultivo cañero, teniendo en cuenta solo tres regiones productivas: zona húmeda, transición y zona seca; y en la etapa de cosecha, solo se llevan a cabo los análisis de varianza de variables agrícolas (población de tallos, longitud, diámetro y rendimiento) y variables de calidad (fibra, humedad, azúcares reductores, sacarosa y toneladas de azúcar por hectárea) (Milanes et al., 2010).

Para abordar esta problemática compleja, el análisis espacial, permite definir, cualitativa y cuantitativamente, el área agrícola de la caña de azúcar y su correlación con las características mencionadas, principalmente con la precipitación, evapotranspiración y los impactos del fenómeno de El Niño (ENSO) y la sequía. Lee-Lovick \& Kirchner (1990) afirmó que, además del clima y las propiedades edáficas, la radiación solar, las prácticas de manejo y gestión, y la infestación de plagas y enfermedades son factores determinantes de la fenología de la planta. En este sentido, Abdel-Rahman \& Ahmed (2008) y Vieira (2000) establecieron que los cultivos agrícolas, como la caña de azúcar, muestran cambios significativos en la respuesta espectral sobre 
imágenes de satélite, como elemento de gestión o gerenciamiento, de acuerdo al ciclo de crecimiento para su manejo en función de la fenología. Esta respuesta espectral responde a la humedad disponible en suelo y se refleja en el vigor vegetal. Por tanto, el análisis de la productividad derivada del agua que recibe el cultivo como precipitación pluvial, durante sus distintas etapas fenológicas corresponde al factor climático que más limita la productividad de acuerdo a las conclusiones de Da Silva et al. (2013); Basnayake et al. (2012); Wiedenfeld (2000) y las revisiones de Carr \& Knox (2011) y Lopes et al. (2011).

Por lo tanto, la geomática constituye un conjunto de herramientas para la gestión del agua como factor limitante; el principal uso de los sensores remotos (RS) y los sistemas de información geográfica (SIG) en el cultivo de caña de azúcar, son la identificación, mapeo, evaluación, seguimiento, manejo y gestión del dosel mediante la interpretación visual o clasificación de imágenes así como caracterizar la fenología, el rendimiento del cultivo, variedad o estrés hídrico. En este sentido, Heuminski de Ávila et al. (2009), Abdel-Rahman \& Ahmed (2008) y Lucas (2007) establecieron que es posible monitorear las variaciones fenológicas de la caña de azúcar, el impacto del acceso al agua como factor limitantes y los cambios derivados del manejo del cultivo con imágenes NOAA-AVHRR (National Oceanic and Atmospheric Administration-Advanced Very High Resolution Radiometer) debido a la alta resolución temporal, junto a los abordajes convencionales estadísticos.

Esto se logra con el análisis previo mediante sensores de alta resolución espectral como Landsat o SPOT para determinar previamente el área cañera. Asimismo, es posible evaluar el comportamiento de la curva del Índice de Diferencia Normalizada de Vegetación (NDVI por sus siglas en inglés), en el rango del ciclo de la caña de azúcar, examinando las composiciones de máximo valor al comienzo, mitad y final del ciclo. Esto indica una correlación con elementos del clima como lluvia, temperatura, índice de sequía, ubicación geográfica, entre otros, los cuales muestran, según Manzo (2009), una coherencia espacial y temporal con las observaciones fenológicas clásicas. Este método ha sido ampliamente utilizado con datos de NDVI, cuando se utiliza el valor máximo de un píxel en una serie de imágenes para construir una composición máxima de un determinado período, registrando el valor más alto para proporcionar un "enmascaramiento" del valor de NDVI o Composiciones de Valor Máximo (MVC) de NDVI para estimar el rendimiento de varios cultivos como caña de azúcar y la medida del estado hídrico de la vegetación (Nascimento et al., 2009, Pettorelli et al., 2005) por lo tanto, es necesario para la región establecer un sistema de información para los parámetros productivos del cultivo de caña de azúcar y evaluar el efecto de los factores limitantes climáticos mediante técnicas geomáticas.

\section{Materiales y métodos}

\section{Zona cañera de la Huasteca Potosina México}

El área de estudio corresponde a la zona cañera conocida como Huasteca Potosina que se localiza en la parte oriental de los estados de San Luis Potosí, Veracruz y Tamaulipas. Los suelos predominantes son vertisoles, rendzina, regosoles, histosoles y luvisoles con profundidad de media a profunda y textura media a fina. El clima dominante es (A) $\mathrm{Cm}$ (Semicálido-húmedo con temperatura media anual de 18 a $22^{\circ} \mathrm{C}$ ), Aw1 (muy cálido subhumedo con temperatura media mayor de $18^{\circ} \mathrm{C}$ ) y Am (cálido húmedo con temperatura media anual de 18 a $22^{\circ} \mathrm{C}$ ) (Figura $\mathrm{N}^{\circ} 3$ ).

De acuerdo a las conclusiones de AguilarRivera et al. (2015, 2013 y 2012), para la Huasteca Potosina existen condiciones favorables para el desarrollo del cultivo de caña de azúcar, y podrían esperarse altos rendimientos tal y como lo mencionaron Salgado (2010); Sánchez et al. (2002) y Bautista et al. (1998). Sin embargo, el factor más importante es la disponibilidad de agua, de acuerdo con lo planteado por Inman-Bamber \& Smith (2005); Jiménez et al. (2004) y Acuña y Zulueta (1996). La caña requiere para su desarrollo por arriba de 1,500 $\mathrm{mm}$ de agua como lluvia y/o riego; en la Huasteca solo el $43 \%$ de los terrenos cañeros presenta la cantidad suficiente para el desarrollo del cultivo en régimen de temporal y altos rendimientos (>80 t/ha). En este sentido, los ingenios azucareros utilizan desde la 
Figura $\mathrm{N}^{\circ} 3$

Temperaturas máximas, mínimas y medias $\left({ }^{\circ} \mathrm{C}\right)$ y precipitación $(\mathrm{mm})$ promedio de la zona cañera de la Huasteca Potosina

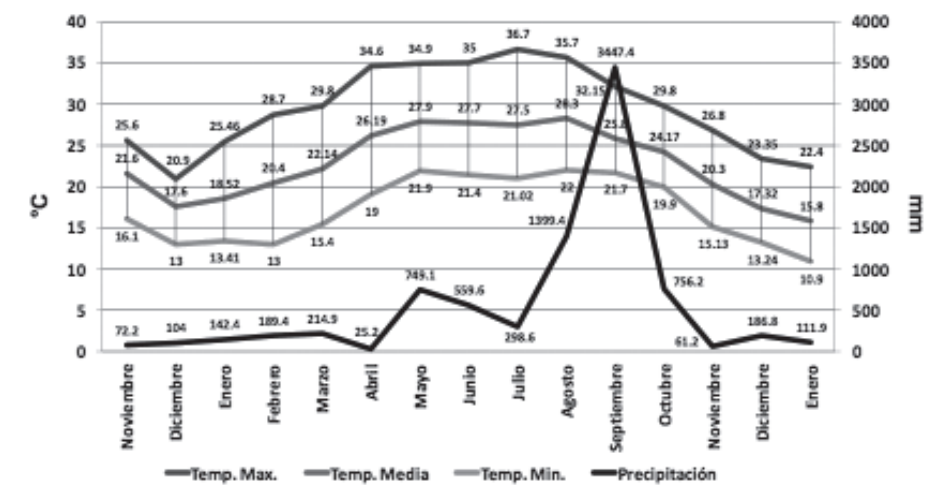

Fuente: Elaboración propia en base a datos de INIFAP (2011).

década de 1970 correlaciones históricas con el agua que recibe el cultivo y otros factores para estimar o predecir la productividad en toneladas de caña/ha (rendimiento de campo y toneladas de sacarosa/ha (rendimiento agroindustrial), como indicador cuantitativo de la planificación de la zafra, plan de caña y azúcar a obtener, determinar el periodo de zafra, inicio y terminación, programar cañas a diferir o buscar la asignación de insumos, equipos de corte, alza y acarreo y búsqueda de mercados (Milanes et al., 2010) (Figura $N^{\circ} 4$ ).
Sin embargo, para determinar el efecto de la precipitación en la zona de estudio se calculó el coeficiente de correlación de Spearman (paquete estadístico STATA) como medida de la correlación (asociación o interdependencia) entre dos variables aleatorias continuas (precipitación y rendimiento). El análisis mostró que el rendimiento no depende de un solo factor sino de la combinación de varios, y la variable precipitación no explica estadísticamente el rendimiento de la caña. Por lo tanto, para determinar de forma

Figura $\mathrm{N}^{\circ} 4$

Precipitación y rendimiento de campo en la zona cañera de la Huasteca

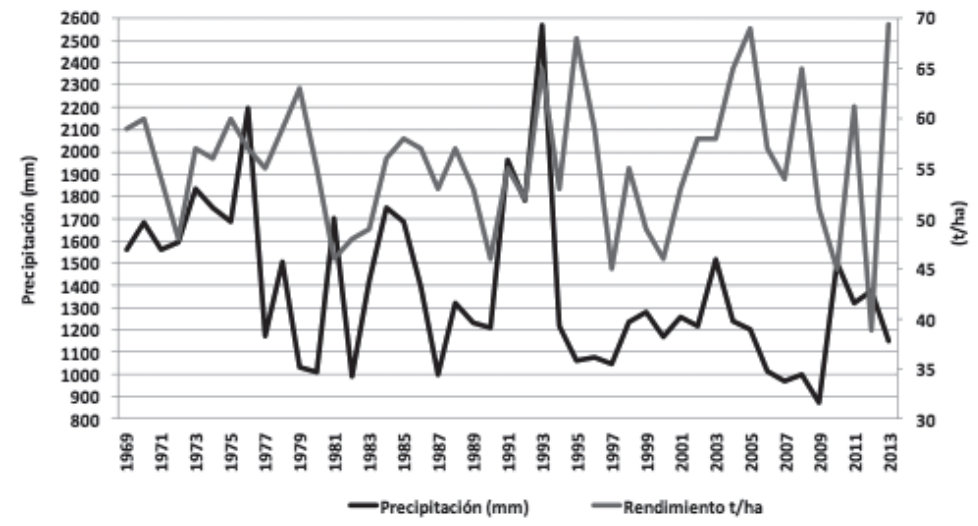

Fuente: Elaboración propia en base a datos del periodo 1969-2013 del Manual Azucarero Mexicano. 
precisa la relación del agua que debería recibir el cultivo de caña de azúcar, como cobertura y uso del suelo en la zona de estudio, se empleó la metodología de análisis espacial, que ha sido ampliamente documentada (Hatfield et al., 2008; Knop, 2007; Almeida et al., 2006; Ueno et al., 2005; Soria-Ruiz, 2004; Xavier et al., 2004; Narciso \& Schmidt, 1999 y Meyer, 1997) con datos del sensor Landsat Thematic Mapper (TM), el cual es capaz de discriminar primeramente la caña de azúcar de otros cultivos mediante un compuesto de falso color y como mapa base para posteriormente modelar espacialmente los factores que permiten explicar las fuentes de variación de la productividad en un área cañera derivadas del acceso al agua (Yang et al., 2011 y Lourenço, 2005). Las imágenes empleadas fueron 2645, 2745 y 2744 (órbita/ punto) adquiridas el día 4 de abril de 2005 (fin de zafra) y el 25 de septiembre de 2007 (inicio de madurez); estas imágenes abarcaron el $100 \%$ del área cultivada con caña de azúcar de acuerdo al trabajo previo de Aguilar-Rivera et al. (2012; 2013), para determinar a priori el área cañera, posteriormente mediante recorridos de campo, la zona cañera fue corregida totalmente con el uso de un equipo GPS Carlson Qmini GIS 360 Edition y la información de campo de los cuatro ingenios (Figura $\mathrm{N}^{\circ}$ 5).

Las imágenes utilizadas para determinar el impacto de los factores climáticos en la zafra azucarera 2008-2010 (14 en total, correspondiente a cada mes de la zafra) fueron

Figura $\mathrm{N}^{\circ} 5$

Zona productora de caña de azúcar de San Luis Potosí México.

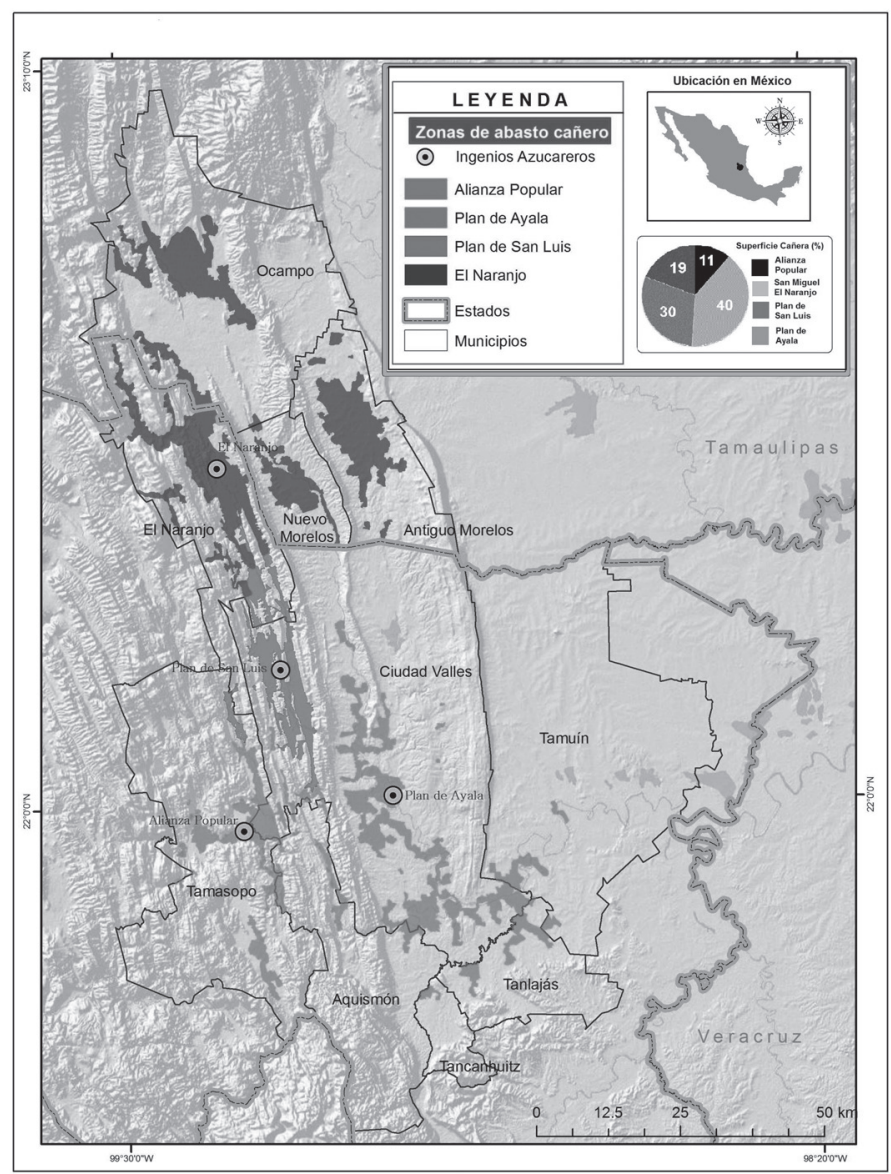

Fuente: Elaboración propia. 
obtenidas del satélite NOAA-AVHRR 17, 18 y 19 con resolución espacial nominal de $1,1 \times$ $1,1 \mathrm{~km}^{2}$ por pixel. Cada imagen cubre zonas de 2.700 a $3.000 \mathrm{~km}$ en sus lados, por lo que se tiene una cobertura regional del $100 \%$ de la zona en estudio. Para la generación del perfil de NDVI y su posterior análisis con datos climáticos (precipitación, evaporación, ENSO, etc.) se consideraron solo los píxeles con caña de azúcar (polígono cañero) en la escala NDVI en Niveles Digitales ND (0-255) durante los periodos de zafra y no zafra en ciclo soca (enero-diciembre), las cuales se importaron las bandas AVHRR $1\left(\rho_{1}\right)(0,58$ a $0,68 \mu \mathrm{m}$ - rojo) y AVHRR $2\left(\rho_{2}\right)(0,72$ a 1,10 $\mu \mathrm{m}$ - infrarrojo cercano) de la serie de satélites NOAA para generar imágenes del Índice de Vegetación de Diferencia Normalizada (NDVI) de Tucker (1979):

$$
N D V I=\frac{\rho_{2}-\rho_{1}}{\rho_{2}+\rho_{1}}
$$

Esto corresponde a la relación NDVI $=$ $(\mathrm{NIR}-\mathrm{VIS}) /(\mathrm{NIR}+\mathrm{VIS})$ o NDVI NOAA $=$ (Canal 2 - Canal 1) / (Canal 2 + Canal 1) y a la respuesta espectral de la caña de azúcar bajo ciertas condiciones agroclimáticas proporcionando datos para el monitoreo de la vegetación para posteriormente ser convertidos a la escala $-1.0<\mathrm{NDVI}<1.0$ para sus valores extremos. Para determinar el efecto de los componentes temperatura y precipitación sobre el NDVI en la zona seleccionada y la caracterización climática se analizaron los registros de temperaturas máximas y mínimas $\left({ }^{\circ} \mathrm{C}\right)$, precipitación $(\mathrm{mm})$ y evapotranspiración $(\mathrm{mm})$, procedentes de las estaciones de la Red Nacional de Estaciones Agroclimáticas de la zona cañera cuyos registros publica el Instituto Nacional de Investigaciones Forestales Agrícolas y Pecuarias (INIFAP) de la Secretaría de Agricultura, Ganadería, Desarrollo Rural, Pesca y Alimentación (SAGARPA): 5 de Mayo, Estación Coyoles, Plan de Ayala, La Hincada, Tampaya, El Estribo, El Encanto, Tancojol, Rancho el Canal, Tamasopo y El Rosario

\section{Potencial hídrico del cultivo de caña de azúcar en la Huasteca México}

Los valores de NDVI, durante la estación de crecimiento en la región, se caracterizaron en sus valores por registrar la tendencia gene- ral de acumulación de biomasa en hojas y taIlos de acuerdo a lo reportado por Palaniswami et al., 2011; Gonçalves, 2008; Smit \& Singels, 2006; Pettorelli et al., 2005; Scarpari \& Gomes Ferreira de Beauclair, 2004 y Pellegrino, 2001; al variar de 0,879 (noviembre) a 0,211 (abril). Las precipitaciones durante los meses de invierno, al inicio de la temporada de cosecha, rebrote o brotación de las yemas vegetativas y al final del ciclo solo, lograron acumular 882,63 mm en promedio; durante el periodo de crecimiento, lo que en teoría no permitió satisfacer las necesidades hídricas del cultivo (Inman-Bamber, 2005) con un déficit de -571,423 mm. Esta situación se presentó de forma crítica para la zona cañera de las estaciones de El Rosario en el Naranjo y 5 de mayo en Ciudad Valles al presentar valores negativos durante todo el ciclo de crecimiento de la caña. Caso contrario a las zonas cañeras de las estaciones Coyoles, Tampaya (Cd. Valles) y El Encanto (San Vicente) que registraron un balance positivo entre la precipitación y la evapotranspiración (Figuras $\mathrm{N}^{\circ} 6$ y $N^{\circ} 7$ ), es decir, el potencial de precipitación retenida por el suelo fue positivo.

Para el análisis del fenómeno ENSO, Borisova (2009); Bonilla et al. (2003); Everingham et al. (1998) y Solow et al. (1998) expusieron que en el proceso agroindustrial de la producción de azúcar, la influencia del ENSO en la temporada invernal provoca más lluvia que lo normal, a veces más cálida y otras veces más fría en términos de desviaciones positivas o negativas de las variables precipitación y temperatura; si llueve durante la estación de maduración y sazonado, es decir de octubre a diciembre, en años La Niña se afecta considerablemente la zafra y el proceso de maduración, la caña produce más hojas y biomasa que tallos al permitir que la lluvia excedente continúe el desarrollo foliar y provocar que la acumulación de sacarosa se detenga, lo cual explica los bajos rendimientos de campo al retrasar la maduración durante noviembre y prolongarse hasta enero o febrero. El fin de La Niña fuerte 2008/2009 y el inicio de El Niño fuerte 2009 provocó en la temporada la drástica caída del valor de NDVI y efectos en la zafra 2008/2009 de la Huasteca Potosina donde, según datos del Manual Azucarero Mexicano 2010 (CNIAA, 2010), se reportó un retraso en el inicio de la zafra debido al exceso de lluvia durante noviembre y diciembre 
Figura $\mathrm{N}^{\circ} 6$

Precipitación $(\mathrm{mm})$ y NDVI de la zona cañera de la Huasteca Potosina

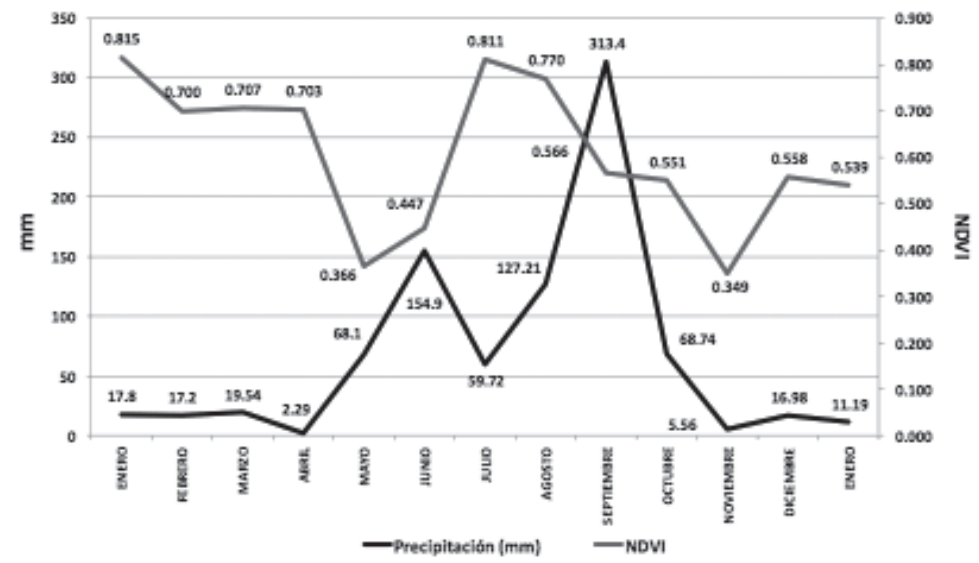

Fuente: Elaboración propia en base a Zafra 2008/2010.

Figura $\mathrm{N}^{\circ} 7$

Potencial de precipitación retenida $(\mathrm{mm})$ y NDVI de la zona cañera de la Huasteca Potosina

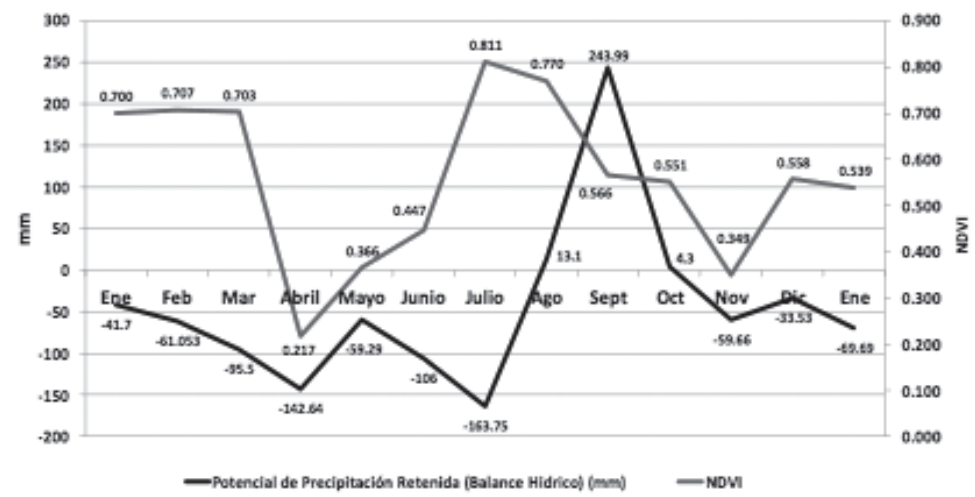

Fuente: Elaboración propia en base a Zafra 2008/2009.

del 2008 y enero del 2009 en los Ingenios Alianza Popular (25 de enero de 2009), Plan de Ayala (11 de enero de 2009), Plan de San Luis (12 de diciembre de 2008), y San Miguel del Naranjo (30 de noviembre de 2008) (Figuras $\mathrm{N}^{\circ} 8$ y $\mathrm{N}^{\circ} 9$ ).

En las series históricas es posible comprobar el efecto de este fenómeno en los rendimientos de campo (t/ha), lo que establece la gran dependencia y debilidad de la zona cañera de la Huasteca Potosina ante la va- riabilidad de los fenómenos climáticos como El Niño, principalmente en los años de tipo fuerte.

Si bien las temperaturas se mantuvieron en el umbral óptimo al presentarse un verano cálido $\left(26,7^{\circ} \mathrm{C}\right)$ con un pico de temperatura máxima promedio en agosto $\left(35,7^{\circ} \mathrm{C}\right)$, durante la etapa de máximo desarrollo del dosel cañero, junto al factor precipitación (promedio $127,2 \mathrm{~mm})$, registró el máximo desarrollo vegetal (NDVI 0,811). Por otra parte, el otoño 
Figura $\mathrm{N}^{\circ} 8$

NDVI en la zona cañera de la Huasteca Potosina (Fin de La Niña Fuerte 2008/2009 e inicio del Niño Fuerte 2009/2010)

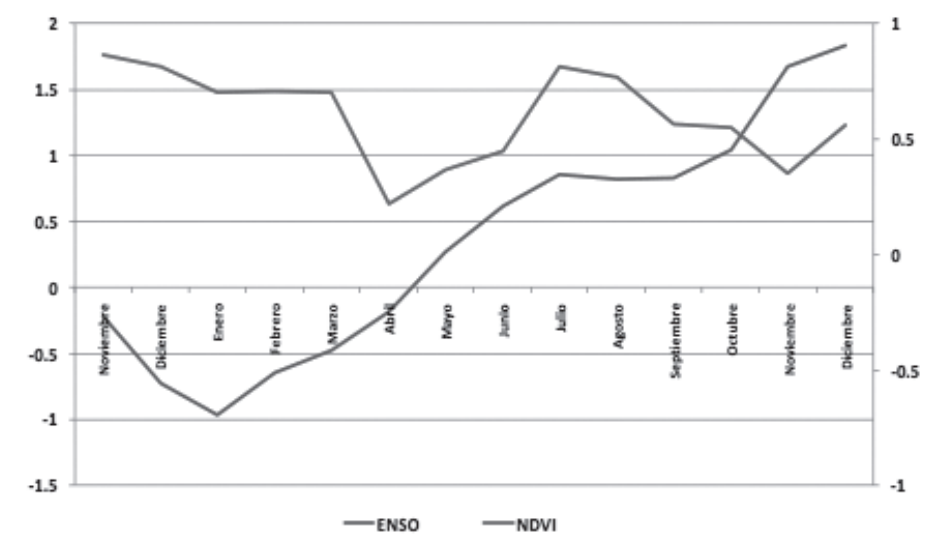

Fuente: Elaboración propia.

Figura $N^{\circ} 9$

Composiciones de Valor Máximo (MVC) de NDVI por nivel de productividad NOAA-AVHRR a) Marzo 2009. Fase inicial estación de crecimiento, b) Octubre 2009 Fase final estación de crecimiento

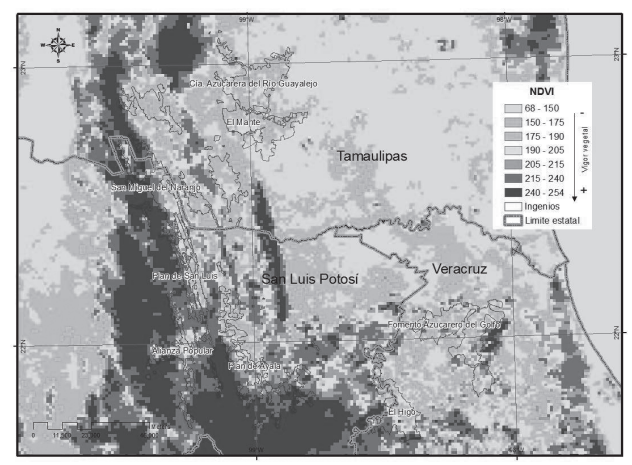

Fuente: Elaboración propia.

semicálido $\left(22,3^{\circ} \mathrm{C}\right)$ donde las temperaturas promedio comenzaron a descender durante el mes de octubre $\left(24,2^{\circ} \mathrm{C}\right)$, aunque presentaron condiciones favorables, estación seca, soleada y fresca para que el cultivo alcanzara la madurez y sazonado a partir de noviembre del 2009, se reflejó en la caída de la curva del NDVI a partir de octubre con un valor de 0,550 que establece el fin del ciclo fenológico.

Es decir, durante el año agrícola la temperatura media no fue menor a $21^{\circ} \mathrm{C}$, por lo que

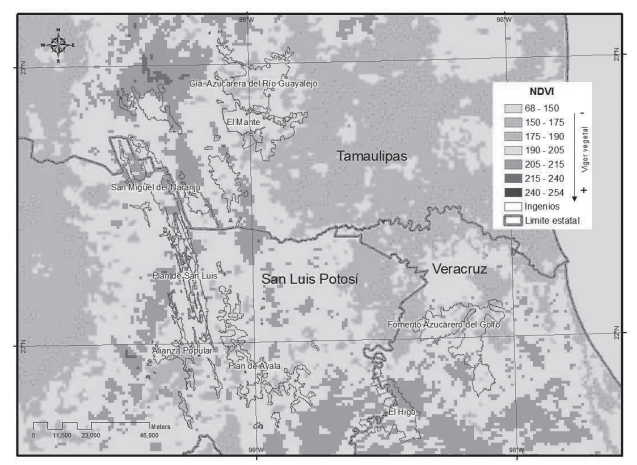

no se retardó el crecimiento de los tallos. Si bien la temperatura no fue una limitante para el cultivo, la zona cañera se clasifica como apta (Cuadro $\mathrm{N}^{\circ} 1$ ).

Salgado (2010) determinó que la precipitación para las condiciones de las zonas cañeras de México, durante los meses de enero a abril se clasifica como año húmedo si esta es superior a los $420 \mathrm{~mm}$, semihúmedo si el rango es de 300 a $420 \mathrm{~mm}$ y seco si no supera los $300 \mathrm{~mm}$. 
Cuadro $\mathrm{N}^{\circ} 1$

Características del clima y las condiciones de desarrollo del cultivo de caña de azúcar

\begin{tabular}{|c|c|c|c|}
\hline $\begin{array}{l}\text { Temperatura promedio } \\
\qquad\left({ }^{\circ} \mathrm{C}\right)\end{array}$ & Clasificación & $\begin{array}{l}\text { Déficit anual } \\
(\mathrm{mm})\end{array}$ & Clasificación \\
\hline$<18$ & No Apto & $<240$ & Apto \\
\hline $18-19$ & Límite de aptitud & $240-300$ & Aptitud media \\
\hline $19-21$ & Marginal & $300-400$ & Límite de aptitud \\
\hline $21-26$ & Apto & $400-600$ & $\begin{array}{l}\text { Límite con } \\
\text { restricciones }\end{array}$ \\
\hline \multirow[t]{2}{*}{$>26$} & Límite de aptitud & $600-800$ & No Apto con ajustes \\
\hline & No apto & $>800$ & No Apto \\
\hline
\end{tabular}

Fuente: Elaboración propia en base a Brunini (2010).

La Huasteca Potosina se puede considerar como una zona con fuertes limitaciones al acumular en promedio durante el periodo de secas solo $120,6 \mathrm{~mm}$ con un déficit de -571.4 $\mathrm{mm}$ en promedio, lo cual clasifica a la zona cañera como límite con restricciones principalmente en los meses de enero a abril y hasta la etapa fenológica 4 (75 a 100\% de cobertura del dosel) y antes de la madurez y sazonado (Figura $\mathrm{N}^{\circ} 10$ ).

Figura $\mathrm{N}^{\circ} 10$

Diferencial evapotranspiración-precipitación durante zafra 2009/2010

(Déficit en las etapas 1 a 4 y 6 a 7)

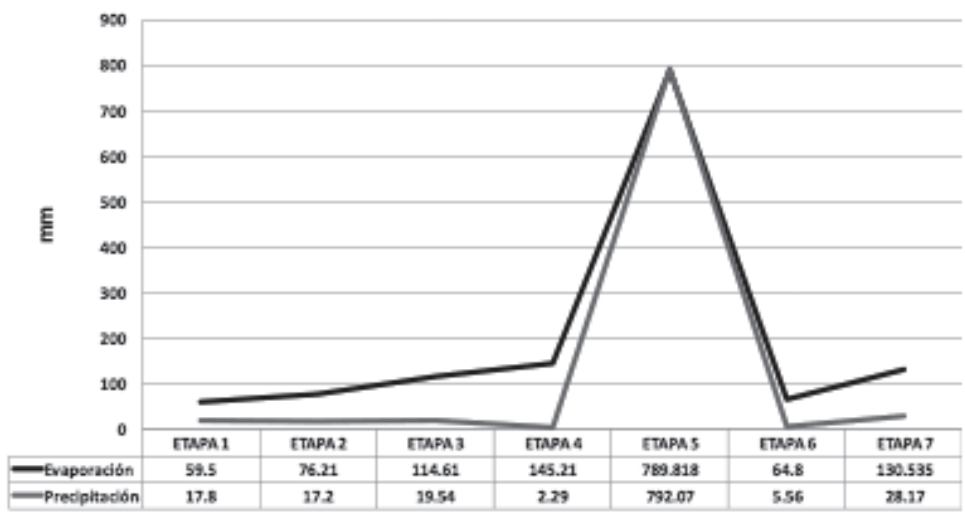

Fuente: Elaboración propia.

Sin embargo, estos indicadores no establecen con precisión los períodos de déficit o exceso y el efecto del clima, es decir, la necesidad de agua de un cultivo, o la cantidad de agua requerida para compensar la pérdida por la evaporación y transpiración que altera significativamente el rendimiento del cultivo de caña de azúcar (Allen, 2006). Una forma de evaluar el impacto del clima (precipitación principalmente) sobre la producción de 
caña de azúcar puede ser a través de la utilización de índices en lugar de utilizarlos de forma individual. Como ejemplo, el Índice de Satisfacción de Necesidades Hídricas (ISNH), calculado por la simulación del balance hídrico durante el ciclo del cultivo del cultivo, el cual se obtiene con la ecuación:

$$
I S N H=\frac{P \rho^{*}(100)}{N H}(1)
$$

Donde Pp precipitación y $\mathrm{NH}$ necesidad hídricas del cultivo siendo

$$
N H=E T \rho * \operatorname{KCr}(2)
$$
$(\mathrm{mm})$

Donde ETp evapotranspiración potencial

$\mathrm{K} c r=$ coeficientes del cultivo de caña de azúcar por etapa fenológica
Este índice expresa la relación entre la oferta de agua como lluvia o riego, la cantidad que es consumida por la planta y que sería deseable para garantizar su máxima productividad y la capacidad de almacenamiento de agua en el suelo. El índice oscila entre cero y uno, siendo el más alto cuando la cantidad de agua almacenada en el suelo es máxima (Gonçalves, 2008). El cálculo de la evapotranspiración del cultivo bajo estas condiciones supone que no existen limitaciones severas por estrés hídrico o salino, densidad del cultivo y dosel, plagas y enfermedades, presencia de malezas o baja fertilidad. Debido a las variaciones en las características propias del cultivo durante las diferentes etapas de crecimiento, Kc cambia desde la siembra hasta la cosecha. En la Figura $N^{\circ} 11$ se presentan en forma esquemática dichos cambios.

Figura $\mathrm{N}^{\circ} 11$

Curva generalizada de Coeficiente de Cultivo Kc

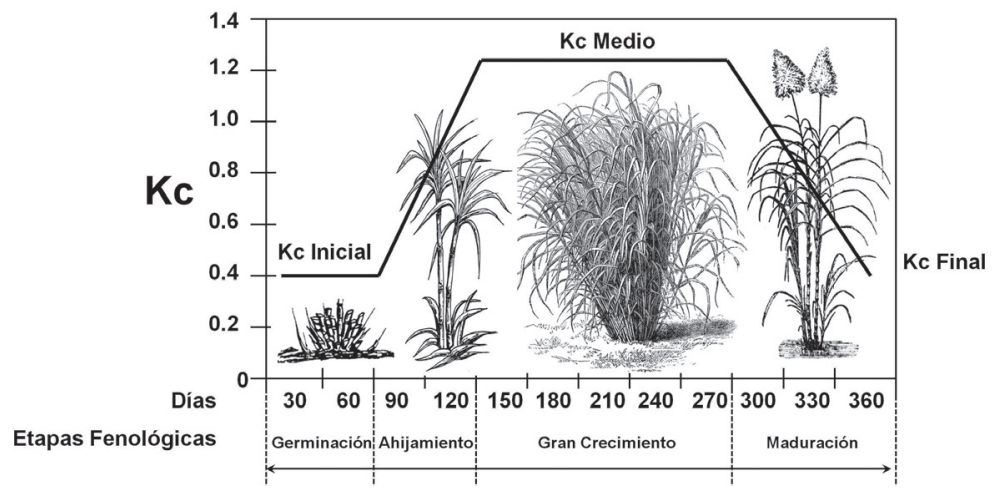

Fuente: Allen (2006).

Los efectos combinados, tanto de la transpiración del cultivo, como de la evaporación del suelo, se integran en este coeficiente único del cultivo (Kc). Así, Kc incorpora las características del cultivo y los efectos promedios de la evaporación en el suelo (Cuadro N²).

Para calcular las necesidades hídricas de la zona cañera se determinó que el cultivo de caña de azúcar presenta la misma fase de crecimiento vegetativo en "caña soca" con el ciclo de crecimiento de un año tomando los datos de precipitación de la zona cañera durante la zafra 2009/2010 por etapa fenológica y por estación meteorológica para determinar las necesidades hídricas del cultivo en la Huasteca Potosina (Cuadro $N^{\circ} 3$ ) de acuerdo a la metodología de Da Silva et al. (2013); Brunini (2010), Gonçalves (2008), Allen (2006) y Scarpari \& Gomes Ferreira de Beauclair (2004) y las ecuaciones 1 y 2.

Para la zona cañera de estudio, se requieren por lo menos $1.364,23 \mathrm{~mm}$ por ciclo 
Cuadro $\mathrm{N}^{\circ} 2$

Coeficientes de cultivo (Kcr) por etapa fenológica para caña de azúcar

\begin{tabular}{|l|r|r|}
\hline \multicolumn{1}{|c|}{ Etapas de desarrollo } & \multicolumn{1}{c|}{ Días } & \multicolumn{1}{c|}{$\begin{array}{c}\text { Coeficiente de } \\
\text { cultura (Kc) }\end{array}$} \\
\hline Etapa 1 (siembra a 25\% de cobertura del dosel) & $30-60$ & 0.50 \\
Etapa 2 (25 a 50\% de cobertura del dosel) & $30-40$ & 0.80 \\
Etapa 3 (50 a 75\% de cobertura de dosel) & $15-25$ & 0.95 \\
Etapa 4 (75 a 100\% de cobertura del dosel) & $45-55$ & 1.10 \\
Etapa 5 (cubrimiento total) & $180-330$ & 1.15 \\
Etapa 6 (madurez temprana) & $30-150$ & 0.95 \\
Etapa 7 (maduración) & $30-60$ & 0.70 \\
\hline
\end{tabular}

Fuente: Gonçalves, 2008; FAO, 2006; Allen, 2006, Jiménez et al., 2004; Doorenbos y Kassan, 1979.

Cuadro $\mathrm{N}^{\circ} 3$

Necesidades hídricas en la zona cañera

\begin{tabular}{|l|r|r|r|}
\hline Etapas de desarrollo & Días & $\begin{array}{c}\text { Necesidades } \\
\text { Hídricas (mm/día) }\end{array}$ & $\begin{array}{c}\text { Por etapa de } \\
\text { desarrollo (mm) }\end{array}$ \\
\hline Etapa 1 (siembra a 25\% de cobertura del dosel) & 30 & 0,991 & 29,75 \\
Etapa 2 (25 a 50\% de cobertura del dosel) & 30 & 2,03 & 60,97 \\
Etapa 3 (50 a 75\% de cobertura de dosel) & 15 & 3,63 & 108,88 \\
Etapa 4 (75 a 100\% de cobertura del dosel) & 45 & 5,32 & 159,73 \\
Etapa 5 (cubrimiento total) & 180 & 5,04 & 908,29 \\
Etapa 6 (madurez temprana) & 30 & 2,05 & 61,56 \\
Etapa 7 (maduración) & 30 & 1,168 & 35,05 \\
Total & 360 & & $1.364,23$ \\
\hline
\end{tabular}

Fuente: Elaboración propia.

fenológico anual para cubrir las necesidades hídricas de la caña. Los mayores valores de necesidades hídricas $(\mathrm{NH})$ del cultivo para esta región se obtuvieron en la etapa fenológica 5 (cubrimiento total del dosel) con requerimientos de 5,04 mm/día. Las $\mathrm{NH}$ más bajas se encontraron en la etapa fenológica de siembra-brotación (Etapa 1), siendo estos de $0,991 \mathrm{~mm} /$ día. En la última etapa fenológica, correspondiente a maduración, las $\mathrm{NH}$ se asemejan a las de la etapa 1 . El valor de $1.364,23 \mathrm{~mm}$ resulta consistente con el determinado por Jiménez et al. (2004) para la zona cañera del sur de Tamaulipas y Norte de San Luis Potosí con 1.452,1 mm. Para el cálculo del Índice de Satisfacción de las Necesidades Hídricas de los Cultivos (ISNH) se emplearon los datos de precipitación y de las necesidades hídricas del cultivo por etapa fenológica (Cuadro $\mathrm{N}^{\circ} 4$ ).

Por lo tanto, la zona cañera presenta déficit hídrico (Relación $\mathrm{P} / \mathrm{NH} \leq 0,5$ ), la distribución de la precipitación pluvial para las etapas fenológica 3 y 4 no es suficiente, mientras que en la etapa 5 se presenta un exceso. Almeida \& Bremm Soares (2008) y Da Silva \& Alexandre (2005) establecieron que variables como precipitación, evapotranspiración, cantidad de agua almacenada en el suelo, 
Cuadro $\mathrm{N}^{\circ} 4$

ISNH de la zona cañera de la zona cañera

\begin{tabular}{|l|r|r|r|}
\hline Etapas de desarrollo & Días & $\begin{array}{l}\text { Necesidades Hí- } \\
\text { dricas (mm/día) }\end{array}$ & ISNH (\%) \\
\hline Etapa 1 (siembra a 25\% de cobertura del dosel) & 30 & 0,991 & 59,83 \\
Etapa 2 (25 a 50\% de cobertura del dosel) & 30 & 15 & 2,03 \\
Etapa 3 (50 a 75\% de cobertura de dosel) & 45 & 3,63 & 28,21 \\
Etapa 4 (75 a 100\% de cobertura del dosel) & 180 & 5,32 & 17,95 \\
Etapa 5 (cubrimiento total) & 30 & 5,04 & 1,43 \\
Etapa 6 (madurez temprana) & 360 & 2,05 & 121,86 \\
Etapa 7 (maduración) & & 1,168 & 9,03 \\
Total/Promedio anual & & 48,45 \\
\hline
\end{tabular}

Fuente: Elaboración propia.

disponibilidad para las plantas y drenaje ejercen influencia directa sobre el potencial de precipitación retenida por el suelo y determinan el valor del NDVI cañero como indicador de productividad para la Huasteca Potosina. Debido a que el valor del NDVI es sensible a las variaciones del biomasa a lo largo del año (Figura $N^{\circ} 12$ ), la cual presenta asociación directa con las condiciones meteorológicas en cada región y según Castro (2010), Moore (2009) y Jiménez et al. (2004) deben también definir las prácticas de preparación de suelos, abonamiento y fertilización, repoblación y volteo de cepas, control de plagas y malezas, selección de variedades. De acuerdo a que la falta de agua afecta drásticamente la productividad de la caña, el riego se justifica como un recurso tecnológico indispensable en el aumento de la productividad de los cultivos en regiones donde la insuficiencia o mala distribución de las lluvias hacen inviable la explotación agrícola.

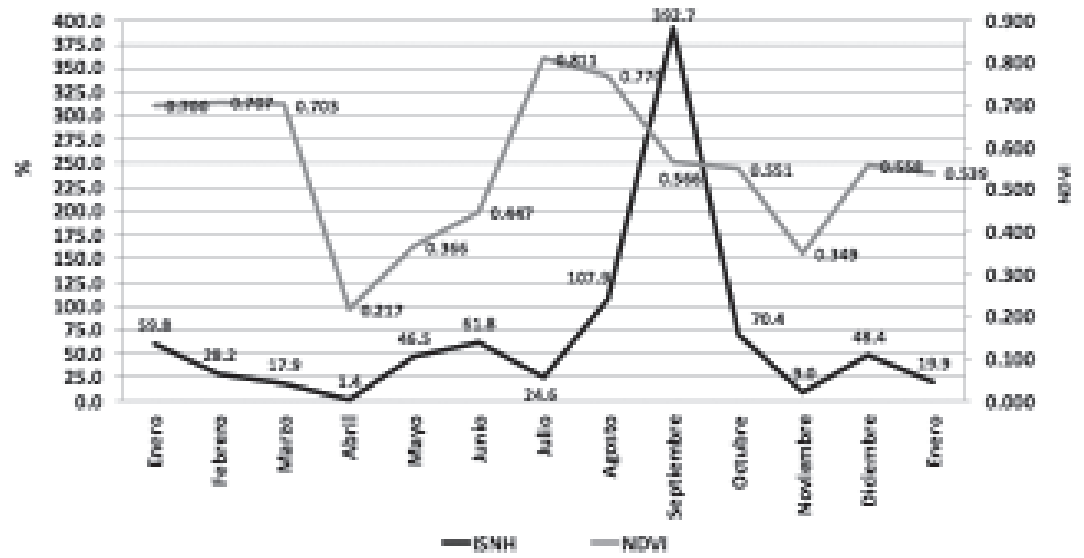

Fuente: Elaboración propia. 
Por lo tanto, el déficit hídrico de enero a mayo que corresponde a la fase de brotación después de la cosecha, para la zona cañera, tiene resultados consistentes con el índice NDVI al presentar una caída considerable a partir de marzo y abril al satisfacer solo el $17,9 \%$ y $1,4 \%$ de las necesidades hídricas, caracterizado por regiones con suelo expuesto y poca vegetación derivado de las necesidades de agua del cultivo. Posteriormente se inicia su recuperación durante el mes de junio, derivado de las precipitaciones de mayo, al incrementar a $46 \%$ el ISNH al inicio de su desenvolvimiento vegetativo (Cuadro $\mathrm{N}^{\circ} 5$ ). Sin embargo el exceso de agua en agosto y septiembre no reflejan esta tendencia debido a que la sequía previa generó un desarrollo foliar bajo. Es decir, la satisfacción de las necesidades hídricas desde el plantío o brotación hasta el estado de máximo crecimiento (julio y agosto) determinan la formación de la biomasa vegetal, y el inicio de la senescencia y maduración hacen que el NDVI vuelva a caer a pesar de las intensas precipitaciones de septiembre. Por lo tanto, los períodos de secas prolongados decisivamente influyen en la producción final y en la respuesta espectral de la caña de azúcar. Con esto se afirma que el ISNH determina el valor de NDVI.

\section{Cuadro $\mathrm{N}^{\circ} 5$}

ISNH (Periodo enero 2009/enero 2010)

\begin{tabular}{|l|r|}
\hline \multicolumn{1}{|c|}{ Mes } & \multicolumn{1}{|c|}{ ISNH (\%) } \\
\hline Enero & 59,83 \\
\hline Febrero & 28,21 \\
\hline Marzo & 17,95 \\
\hline Abril & 1,43 \\
\hline Mayo & 46,49 \\
\hline Junio & 61,81 \\
\hline Julio & 24,56 \\
\hline Agosto & 107,92 \\
\hline Septiembre & 392,68 \\
\hline Octubre & 70,36 \\
\hline Noviembre & 9,03 \\
\hline Diciembre & 48,45 \\
\hline Enero & 19,87 \\
\hline
\end{tabular}

Fuente: Elaboración propia.
En este sentido, Romero (2009) sostiene que las condiciones térmicas e hídricas asociadas a las épocas de plantación o brotación constituyen los factores que prácticamente explican la dinámica de las fases iniciales de la caña. Si bien el período crítico para el cultivo se centra en los meses de junio a agosto, indudablemente el crecimiento alcanzado en las fases iniciales ejerce un efecto notable en el desarrollo del cultivo. Esto provoca disminuciones del orden del $43 \%$ en el aprovechamiento del período de gran crecimiento y destaca la elevada sensibilidad de la planta de caña al déficit hídrico en el rendimiento cultural mediante el rápido establecimiento de un elevado número de tallos primarios, la generación y expansión del sistema foliar y radicular y un inicio temprano del macollaje. Estos factores influyen en la determinación de la población final de tallos. Además, asociados con la velocidad de ocurrencia, influyen en la capacidad competitiva del cultivo con las malezas (cierre temprano del cañaveral) y en el aprovechamiento adecuado de los recursos ambientales y de manejo para enfatizar la importancia del mantenimiento de niveles hídricos adecuados durante todo el ciclo del cultivo para el logro sostenido de altas producciones de la planta. Humbert (1974) estableció que los excesos durante la estación lluviosa pueden reducir las tasas de crecimiento, y en suelos con drenaje deficiente, particularmente para los suelos tipo vertisol de la Huasteca, pueden disminuir la cantidad de radiación directa disponible para la caña. Esto hace ineficientes las labores de cultivo como el control de malezas y la fertilización de modo que la caña madura tardíamente $y$, en consecuencia, el contenido de azúcar almacenada en el tallo se reduce. Para Greenland (2005) los altos valores de rendimiento de caña de azúcar tienen más probabilidades de ser alcanzados durante los años en los que la precipitación es menor a 6,4mm/día durante agosto y septiembre.

Para la Huasteca se registraron 4,24 mm en agosto y 10,45 mm en septiembre. Por otro lado, cuando el excedente de agua del suelo es menor a lo largo de la temporada de crecimiento, es decir, si las precipitaciones son inferiores durante agosto y la temperatura máxima es superior a la media, los períodos de cobertura de nubes son menores y los valores de radiación son más altos en el dosel; 
para la zona de estudio, esta condición se cumple para el mes de agosto al registrar la temperatura media más alta $28,3^{\circ} \mathrm{C}$ y máxima con $36,65^{\circ} \mathrm{C}$. Esta situación contribuiría a estimular el crecimiento temprano (Etapa 5), tanto de la caña planta y soca, para obtener mayores rendimientos. De acuerdo a las conclusiones de los autores referidos, los valores de vigor vegetal NDVI de la zona cañera resultaron consistentes con las condiciones climáticas durante la zafra 2008/2009 e intervienen en la productividad de zafra azucarera, por lo que debería esperarse una productividad media a baja, es decir, un rendimiento de campo de 70-60 t/ha y un rendimiento agroindustrial mayor a 7,5 t/ha. Sin embargo, durante la temporada 2008/2009, el Manual Azucarero Mexicano (2010) reportó rendimiento de campo de 51.025 t/ha y agroindustrial de 6,22 t/ha, muy inferior a lo esperado y menor al promedio nacional $(21,5 \%$ por debajo de la media nacional).

\section{Conclusiones}

El crecimiento y la productividad de caña de azúcar, bajo riego y secano, declinan al incrementarse la edad del cultivo (resocas) debido a que su capacidad para responder a determinadas condiciones climáticas no favorables como la sequía y el estrés hídrico, característico de la región de estudio, también disminuye; ello repercute, por lo tanto, en su calidad agroindustrial como materia prima y los cambios en la productividad (tha ${ }^{-1}$ ) provocan alteraciones en las decisiones de siembra, uso de insumos y factores productivos, lo cual afecta a la rentabilidad $y$, finalmente, al bienestar de productores y consumidores.

Como resultado de este trabajo, se determinó que la zona cañera requiere al menos $1.364,23 \mathrm{~mm}$ de agua como Iluvia o riego por ciclo fenológico anual para cubrir las necesidades hídricas y mantener la productividad, sin embargo, solo obtiene el $41 \%$, lo que hace que esta zona productora sean inviable por los bajos rendimiento (por debajo de 50 tha- $^{1}$ ) derivados del acceso al agua.

Los perfiles de NDVI obtenidos mediante imágenes de satélite y técnicas de percepción remota, representan un insumo a ser empleado en la zona, con la finalidad de dirigir a la toma de decisiones sobre la cantidad de agua y los sistemas de gestión de la misma que necesita el cultivo para alcanzar su máxima producción empleando de manera sinérgica las metodologías convencionales y el uso de tecnologías de agricultura de precisión de forma complementaria también para el desarrollo de variedades, mecanización y la minimización de insumos derivados de combustibles fósiles y costos de producción.

\section{Referencias bibliográficas}

ABDEL-RAHMAN, E.M. \& AHMED, F.B. The application of remote sensing techniques to sugarcane (Saccharum spp. hybrid) production: a review of the literature. International Journal of Remote Sensing, 2008, Vol. 29, N ${ }^{\circ}$ 13 , p. 3753-3767.

ACUÑA, A.J.L. y ZULUETA, R. Zonificación agroecológica para el cultivo de caña de azúcar en el estado de Veracruz. La Ciencia y el Hombre, 1996, № 22, p. 51-69

AGUILAR-RIVERA, N. \& OLVERA, V.L.A. Agro-ecological Zoning of Mexican Sugarcane Crop Fields. Springer Sugar Tech, 2015, DOI 10.1007/s12355-014-0358-6.

AGUILAR-RIVERA, N.; VARGAS, L.A.O. y GALINDO, M., G. Evaluación de aptitud de tierras al cultivo de caña de azúcar en la Huasteca potosina, México, por técnicas geomáticas. Revista de Geografía Norte Grande, 2013, No 55, p. 141-156.

AGUILAR-RIVERA, N.; GALINDO M., G. \& FORTANELLI M., J. Agro-industrial evaluation sugarcane crop (Saccharum officinarum L.) by SPOT 5 HRV imagery in Huasteca México. Revista Facultad de Agronomía, 2012, Vol. 111, $\mathrm{N}^{\circ} 2$, p. 64-74

ALMEIDA SILVA M., R. \& BREMM SOARES, A. Agronomic performance of sugarcane families in response to water stress. Bragantia Campinas, 2008, Vol. 67, N³, p. 655-661.

ALMEIDA, T.I.R.; DE SOUZA, C.R. \& ROSSETTO, R. ASTER and Landsat ETM+ images applied to sugarcane yield forecast. International Journal of Remote Sensing, 2006, Vol. $27, N^{\circ} 19$, p. 4057-4069. 
ALLEN, R.G. Evapotranspiración del cultivo. Guías para la determinación de los requerimientos de agua de los cultivos. Roma: Organización de las Naciones Unidas para la Agricultura y la Alimentación, Estudio FAO Riego y Drenaje, 2006, Vol. 56.

BAUTISTA, Z.F.; RIVAS S.; H.; DURÁN DE BAZÚA, C. y PALACIO, G. Caracterización y clasificación de suelos con fines productivos en Córdoba, Veracruz, México. Investigaciones Geográficas, 1998, Vol. 36, p. 21-33

BASNAYAKE, J.P.; JACKSON, N.A.; INMAN-BAMBER, G. \& LAKSHMANAN, P. Sugarcane for water-limited environments. Genetic variation in cane yield and sugar content in response to water stress. Journal of Experimental Botany, 2012, Vol. 63, №16, p. 6023-6033

BONILLA, A.; ROSALES, R. y MALDONADO, J. El valor económico de la predicción del fenómeno el niño oscilación del sur ENOS para el sector azucarero colombiano, Documentos CEDE 002565, Universidad de Ios Andes-CEDE. Revista Desarrollo y sociedad, 2003, Vol. 52, p. 1-39.

BORISOVA, T. Economic Approach to Valuing Information with Applications to Climate Information1. Gainesville: Food and Resource Economics Department, Florida Cooperative Extension Service, Institute of Food and Agricultural Sciences, University of Florida, 2009.

BRUNINI, A. Agroclimatic zoning and climatic risks for sugarcane in Mexico-a preliminary study considering climate change scenarios. Proceedings of International Society for Sugar Cane Technology, 2010, Vol. 27, p. $302-314$

CÁMARA NACIONAL DE LA INDUSTRIA AZUCARERA Y ALCOHOLERA (CNIAA). Manual Azucarero Mexicano, 2010, №53.

CARR, M.K.V. \& KNOX, J.W. The water relations and irrigation requirements of sugar cane (Saccharum officinarum): a review. Experimental Agriculture, 2011, Vol. 47, № 1, p. 1-25.

CASTRO, O.R. La variabilidad de la radiación solar en la superficie terrestre y sus efectos en la producción de caña de azúcar en
Guatemala. En: Memorias del XVIII Congreso de Técnicos Azucareros de Centroamérica, El Salvador, 5-8 julio de 2010. Disponible en Internet: http://www.atasal.org/wp-content/ uploads/2010/07/Variabilidad-Solar-y-su-Efecto-en-la-Ca\%C3\%B1a-de-Az\%C3\%BAcar-enGuatemala.-O-Castro.-CENGICA\%C3\%91A.Guatemala.1.doc

DA SILVA, V.D.P.; DA SILVA, B.B.; ALBUQUERQUE, W.G.; BORGES, C.J.; DE SOUSA, I.F. \& NETO, J.D. Crop coefficient, water requirements, yield and water use efficiency of sugarcane growth in Brazil. Agricultural Water Management, 2013, Vol. 128, p. 102-109.

DA SILVA MARQUES, J.R. \& ALEXANDRE, C. Spatial variability of irrigated corn yield in relation to field topography and soil chemical characteristics. Precision Agriculture, 2005, Vol. 6, N 5, p. 453-466.

DOORENBOS, J. \& KASSAN, A. Efectos del Agua sobre el Rendimiento de los Cultivos. Roma: Organización de las Naciones Unidas para la Agricultura y la Alimentación, Estudio Riego y Drenaje, 1979, № 33.

EVERINGHAM, Y.L.; MUCHOW, R.C. \& STONE, R.C. ENSO, the South African climate and sugarcane production. Proc $S$ Afr Sug Technol Ass, 1998, Vol. 72, p.10-14.

FOGLIATA, F.A. Agronomía de la caña de Azúcar. Tucumán: El Graduado, 1995, Vol. 2.

FOOD AND AGRICULTURE ORGANIZATION OF THE UNITED NATIONS (FAO). Crop Water Management for Sugarcane. 2006. Disponible en Internet: http://www.fao.org/ landandwater/aglw/cropwater/sugarcane.stm

FOOD AND AGRICULTURE ORGANIZATION OF THE UNITED NATIONS (FAO). Sugarcane, water relations and water management of sugarcane. 2009. Disponible en Internet: http://www.fao.org/landandwater/aglw/ cropwater/sugarcane.stm.

GONÇALVES, R.R.V. Relação entre a resposta espectral da cana-de-açúcar, registrada nas imagens dos satélites AVHRR/NOAA, em São Paulo, e dados agroclimáticos, no período de 2001 a 2008. Campinas: Faculdade de 
Engenharia Agrícola, Universidade Estadual de Campinas, 2008.

GREENLAND, D. Climate Variability and Sugarcane Yield in Louisiana. Journal of applied meteorology, 2005, Vol. 44, p. 1.6551.666 .

HATFIELD, J.L.; GITELSON, A.A.; SCHEPERS, J.S. \& WALTHALL, C.L. Application of Spectral Remote Sensing for Agronomic Decisions. Agronomy Journal, 2008, Vol. 100, N 3, p. 117-131.

HEUMINSKI DE ÁVILA A.M.; RIBEIRO DO VALLE GONÇALVES, SILVEIRA PINTO \& ZULLO, J. Relação entre a precipitação e o NDVI em imagens AVHRR/NOAA para a cana-deaçúcar, no estado de São Paulo. In: Anais XIV Simpósio Brasileiro de Sensoriamento Remoto, Natal, Brasil, 25-30 abril 2009, INPE, p. 553-560.

HUMBERT, R.P. El cultivo de la caña de azúcar. México: Editorial CECSA, 1974.

HUNSIGI, G. Sugarcane in Agriculture and industry. Bangalore: Eastern Press Pvt Ltd., 2001.

INMAN-BAMBER, N.G. \& SMITH, D.M. Water relations in sugarcane and response to waters deficits. Fields Crops Research, 2005, Vol. 92, p. 185-202.

INSTITUTO NACIONAL DE INVESTIGACIONES FORESTALES, AGRÍCOLAS Y PECUARIAS (INIFAP). Red de estaciones agroclimáticas. 2011. Disponible en Internet: http:// clima.inifap.gob.mx/redinifap/

JIMÉNEZ, C.A.; VARGAS, T.W.V.; SALINAS C., E.; AGUIRRE B., M. y RODRíGUEZ C., D. Aptitud agroecológica para el cultivo de la caña de azúcar en el sur de Tamaulipas. México Investigaciones Geográficas. Boletín del Instituto de Geografía, 2004, Vol. 53, p. 58-74.

KNOP, I. Precision agriculture options for the Australian sugarcane industry. AM SRDC Technical Report 3/2007 Sugar Research and Development Corporation.

LEE-LOVICK, G. \& KIRCHNER, L. The application of remotely sensed (Landsat TM) data to monitor the growth and predict yields in sugarcane. Proceedings of the Australian Society of Sugar Cane Technology, 1990, p. 65-72.
LOPES, M.S.; ARAUS, J.L.; PHILIPPUS, D.; VAN HEERDEN, R. \& FOYER, C.H. Enhancing drought tolerance in C4 crops. Journal of Experimental Botany, 2011, Vol. 62, N 9, p. 3.135-3.153.

LOURENÇO, L. Relação entre atributos do solo e da planta e a resposta espectral da cultura de cana-de-açúcar. Campinas: Faculdade de Engenharia Agrícola, Universidade Estadual de Campinas, 2005.

LUCAS, S.A. Análise do NDVI/NOAA em cana-de-açúcar e Mata Atlântica no litoral norte de Pernambuco. Brasil Revista Brasileira de Engenharia Agrícola e Ambiental, 2007, Vol. 11, № 6, p. 607-614.

MANZO, D.L. Análisis satelital multitemporal de vegetación. En: AGUIRRE GÓMEZ, R. (compilador). Conceptos de geomática y estudios de caso en México: México: UNAMIg serie libros de investigación, 2009, Vol. 5, p. 241-260.

MEYER, A. Review of near infra-red spectroscopy research in the South African sugar industry. Proc S Afr Sug Technol Ass, 1997, Vol. 71, p. 33-37.

MICELI, G.F. Regulación enzimática de la acumulación de sacarosa en cañas de azúcar (Saccharum spp.). Agrociencia, 2002, Vol. 36, $\mathrm{N}^{\circ} 4$, p. 411-419.

MILANES, R.N.; ENRÍQUEZ, R.V.; BELLO, C.M.; SARQUÍS, J.I. \& HERRERA, S.A. Environmental Effects on Yield and Quality in Three Sugarcane Varieties Grown in Veracruz, Mexico. International Journal in Environmental Stress Management, 2010, Vol. 1, p. 198203

MOORE, P.H. Sugarcane Biology, Yield and Potential for Improvement. In: Workshop BIOEN on Sugarcane Improvement, São Paulo 18 y 19 de marzo de 2009. Disponible en Internet: http://www.fapesp.br/materia/5064/ bioen/workshop-bioen-on-sugarcane-improvement-18-e-19-3-2009-.htm

NASCIMENTO, C.R.; ZULLO, J. \& MOURA, B.A. Estimativa de produtividade da cana de-açúcar utilizando séries temporais de imagens AVHRR/NOAA-17 e modelo fenológicoespectral. Revista Brasileira de Ciências Agrárias, 2009, Vol. 4, N³, p. 329-337. 
NARCISO, G. \& SCHMIDT, E. Identification and classification of sugarcane based on satellite remote sensing. Proc. S. Afr. Sug. Technol. Ass., 1999, Vol. 73, p. 189-194.

PALANISWAMI, C.; GOPALASUNDARAM, P. \& BHASKARAN, A. Application of GPS and GIS in sugarcane agriculture. Sugar Tech, 2011, Vol. 13, №4, p. 360-365

PELLEGRINO, G.Q. Utilização de dados espectrais do satélite NOAA14/AVHRR como fonte de dados para modelos matemáticos de estimativa da fitomassa da cana-de-açúcar. Campinas: Tese Doutorado em Engenharia Agrícola, Faculdade de Engenharia Agrícola, Universidade Estadual de Campinas, 2001.

PETTORELLI, N.; VIK, J.O.; MYSTERUD, A.; GAILLARD, J.M.; TUCKER, C.J. \& STENSETH, N.C. Using the satellite-derived NDVI to assess ecological responses to environmental change. Trends in ecology \& evolution, 2005, Vol. 20, №. 9, p. 503-510.

RAMME, P.F.L. Perfis temporais NDVI e sua relação com diferentes tipos de ciclos vegetativos da cultura da cana-de-açúcar. Campinas: Dissertação Doutor em Engenharia, Faculdade de engenharia agrícola, Universidade Estadual de Campinas, 2008.

ROMERO, E.R. Manual del cañero. Tucumán: Estación Experimental Agroindustrial Obispo Colombres (EEAOC), 2009.

SALGADO, S. Lotificación del campo cañero: una metodología para iniciar la agricultura de precisión en ingenios de México. Interciencia, 2010, Vol. 35, №3, p. 183-190.

SÁNCHEZ, P.G.; ORTIZ, S.C. y GUTIÉRREZ, C. Clasificación campesina de tierras y su relación con la producción de caña de azúcar en el sur de Veracruz. Terra, 2002, Vol. 20, N4, p. 359-369.

SCARPARI, M.S. \& GOMES FERREIRA DE BEAUCLAIR, E. Sugarcane maturity estimation through edaphic-climatic parameters. Scientia Agricola, 2004, Vol. 61, №5, p. 486491.
SINGELS, A.; ANNANDALE, J.G.; JAGER, J.D.; SCHULZE, R.E.; INMAN-BAMBER, N.G.; DURAND, W. \& STEYN, J.M. Modelling crop growth and crop water relations in South Africa: Past achievements and lessons for the future. South African Journal of Plant and Soil, 2010, Vol. 27, № 1, p. 49-65.

SMIT, M.A. \& SINGELS, A. The response of sugarcane canopy development to water stress. Field Crops Research, 2006, Vol. 98, $\mathrm{N}^{\circ} 2$, p. 91-97.

SOLOW, A.; ADAMS, R.; BRYANT, K.; LEGLER, D.; O'BRIEN, J.; MCCARL, B.; NAYDA, W. \& WEIHER, R. The value of improved ENSO prediction to U.S. agriculture. Climatic Change, 1998, Vol. 39, p. 47-60.

SORIA-RUIZ, J. Methodology for prediction of corn yield using remote sensing sateIlite data in Central Mexico. Investigaciones Geográficas, 2004, Vol. 55, p. 61-78.

UENO, M.; KAWAMITSU, Y.; SUN, L.; TAIRA, E. \& MAEDA, K. Combined applications of NIR, RS, and GIS for sustainable sugarcane production. Sugar cane international, 2005, Vol. 23, N 4, p. 8-11.

VIEIRA, S.R. Uso de geoestatística em estudos de variabilidade espacial de propriedades do solo. In: NOVAIS, R.F. (editor). Tópicos em ciência do solo. Viçosa: Sociedade Brasileira de Ciência do Solo, 2000, p. 1-54.

YANG, X.; SMITH, P.L.; YU, T. \& GAO, H. Estimating evapotranspiration from terrestrial groundwater-dependent ecosystems using Landsat images. International Journal of Digital Earth, 2011, Vol. 4, № 2, p. 154-170.

XAVIER, A.C.; CARLOS, A.; VETTORAZZI, R. \& MACHADO, E. Relação entre índice de área foliar e frações de componentes puros do modelo linear de mistura espectral, usando imagens ETM+/Landsat. Engenharia Agrícola, 2004, Vol. 24, No 2, p. 421-43.

WIEDENFELD, R. Water stress during different sugarcane growth periods on yield and response to $\mathrm{N}$ fertilization. Agricultural Water Management, 2000, Vol. 43, p. 173-182. 